\title{
AN EMPIRICAL STUDY ON SYSTEM DYNAMICS MODEL FOR SUSTAINABLE DEVELOPMENT OF AIR TRAFFIC CONTROL UNITS
}

\begin{abstract}
With the rapid growth of flight volume, the contradiction between insufficient support capability of air traffic control (ATC) units and large demand for development ultimately hinders their sustainable and safe development. The article aims at the leverage point of the contradiction between supply and demand so as to provide scientific safety policies. Based on the system archetype "growth and underinvestment", from the perspective of the feedback relationships between support capability, safety, and development, the causality of the dynamic factors of control, communication, navigation, and surveillance, as well as meteorology and information subsystems was studied. Then, a system dynamics model for the sustainable and safe development of ATC units was established. Taking the Tianjin ATC sub-bureau as an example, policy suggestions for sustainable and safe development were put forward according to the scenario simulation results.
\end{abstract}

Keywords: air traffic control, support capability, safe, sustainable development, system dynamics

\section{Introduction}

The main task of ATC (air traffic control) units is to manage the airspace, make flight rules and procedures, and provide services for communication, navigation, surveillance, information, and aviation meteorology [1]. The support capability of ATC units cannot match demands for rapid development, leading to frequent unsafe ATC event, reduced flight normality. It is necessary to study the dynamic match between support capability, safety, and development, and how to make policy decisions in the process of rapid growth of flight so as to realize the sustainable and safe development of ATC units.

There is a dynamic and complex feedback relationship between safety and development. Initially, scholars studied safety and development from a single perspective of safety or development. The fluctuation rule of the influence of safety input (people, equipment, environment, and management) on safety level was simulated by system dynamics model of safety management strategy of ATC units [2]. In terms of development, demand prediction models, and dynamic demand capacity balancing dynamic airspace management were used to provide regional air traffic flow management initiatives, and the capacity of an air traffic services depends on the level and type of provided, availability of support and alert systems, ATC workload, equipment performance available and so on [3].

\footnotetext{
${ }^{1}$ College of Economics and Management, Civil Aviation University of China, Tianjin 300300, China, email: f-chen@cauc.edu.cn (F.C.), 17622952684@163.com (X.C.)

${ }^{2}$ Shandong Airlines CO., LTD., Shandong 250000, China, email: 1053266108@qq.com (X.Z.)

*Corresponding author: f-chen@ cauc.edu.cn (F.C.)
} 
However, organizations should bear safety pressures corresponding to development, with rapid development, safety and development are mutually restricted [4]. In the conflicting relationship between rapid development and safety, the key factor of support capability cannot be ignored. Unsafe event will occur when support capability cannot keep up with the pace of development, and this lag will in turn constrain the development. ATC safety support capability consists of 4 index, which are personnel capability, equipment capability, environment capability and management capability [5]. However, how restraint between support capability and sustainable and safe development is to be studied.

Based on the literature review, it was determined that the available research on sustainable and safe development of ATC units has many shortcomings. First, a single perspective of safety or development without considering the demand of support capability caused by the growth of flight volume. Second, four departments restrict each other, but the present literature mainly focuses on single department in particular control, without comprehensive considering communication, meteorology, information, and their interactions.

As an ATC units involves the dynamic matching of a large amount of equipment, various types of personnel, airspace environment and management, etc., it is a dynamic and complex social system, and its sustainable and safe development is restricted by a variety of factors. System dynamics is an effective method to solve complex, nonlinear, and dynamic problems [6,7], which is developed from systems theory and control theory [8]. It was first proposed by Forrester of MIT in 1961. The system dynamics method is composed of feedback loops, variables, and equations [9-11] which emphasize information feedback and use feedback structures to simulate the interaction between internal factors of the system, to clarify the impact of different policies on the system in the future, and to help people understand the complex coupled system behaviour in safety management [12]. Its advantage is that it can provide more reliable short- and medium-term predictions than statistical models, and can provide a means to determine the leverage point of the problem $[13,14]$.

To sum up, this paper focuses on the restriction of support capability, safety, and development, determining the internal interaction of the main factors in four departments so as to build a system dynamics model for sustainable and safe development of ATC units. This model could analyse the dynamic feedback relationship between four subsystems and their internal factors. The model explores the sustainable and safe development mode of ATC units by simulating the safety trends and development trends of ATC units under specific policies.

\section{System dynamic model of ATC units}

\section{Causal loop diagram}

The impact of the increase of flights on ATC units is reflected on the increase of manpower, material resources, and other resource in the four departments. The gaps can cause the support capability to be unable to match the development level. Thus, the number of unsafe event increases and the regularity of flights decreases, which also encourage leadership to take measures of flow control to limit the rapid growth of flights. In this way, the system presents a dynamic characteristic that is out of proportion and out of line [8]. 
Thus, ATC units are in accordance with the feedback rule of the growth and underinvestment archetype [15].

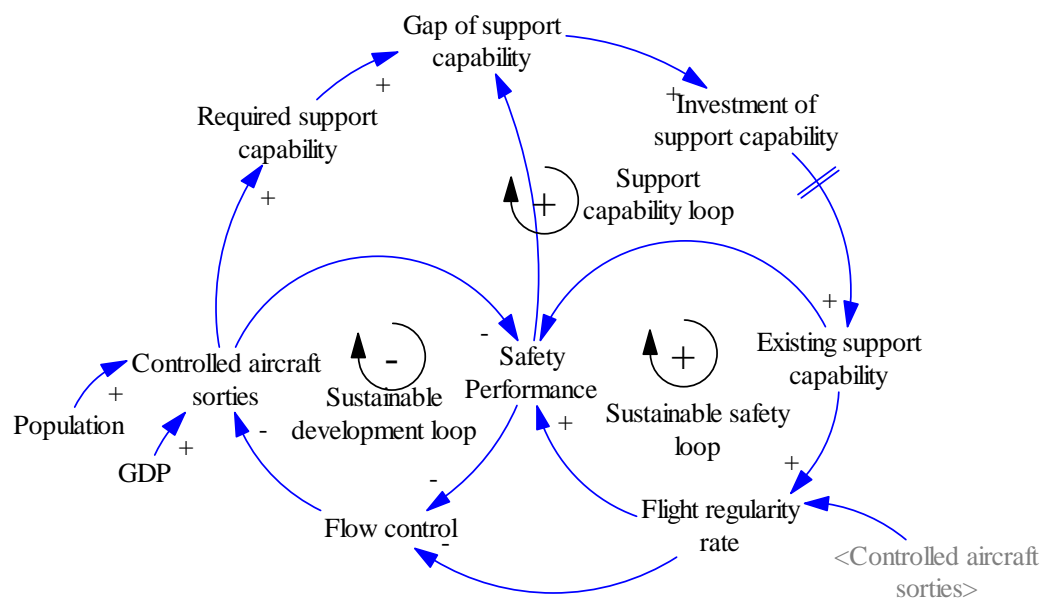

Fig. 1. Conceptual model for the sustainable and safe development of ATC units

Corresponding to the growth and underinvestment archetype, a conceptual model is constructed as shown in Figure 1, which is composed of a support capability loop, sustainable safety loop, and sustainable development loop. Among them, "action to promote growth" is development (controlled aircraft sorties); "demand" mainly includes development demand, safety demand, and service demand; "performance" is the flight regularity rate and unsafe event rate; "performance standards" include "safety goals" and "flight normality goals"; "investment and construction" refers to the investment in ATC support capability; "capacity" refers to the ATC support capability.

\section{Subsystem for the sustainable and safe development of the control department}

The development of flights has brought about increasing demand for controllers. But the growth of the number of controllers has a time delay. Professional ability of controllers affects the safety capability [16] and regularity of flights. In addition, when the knowledge level of the members is relatively consistent, the collocation fitness between the members will be improved and conflict will be reduced. The increase of the number of flights and the working conditions emphasizing safety and timeliness cause controllers to tire and may lead them to operate illegally [17]. Moreover, conflict within the team threatens the safety of operation [18]. The attitude of managers is related to safety culture and supervision strength, so that controllers can actively improve their working attitude [19]. Controlled aircraft sorties are not only affected by the GDP and population [14], but they can be restricted by the unsafe event rates, flight delays, and flow control. So, the causal loop diagram of the control department subsystem in Figure 2. 


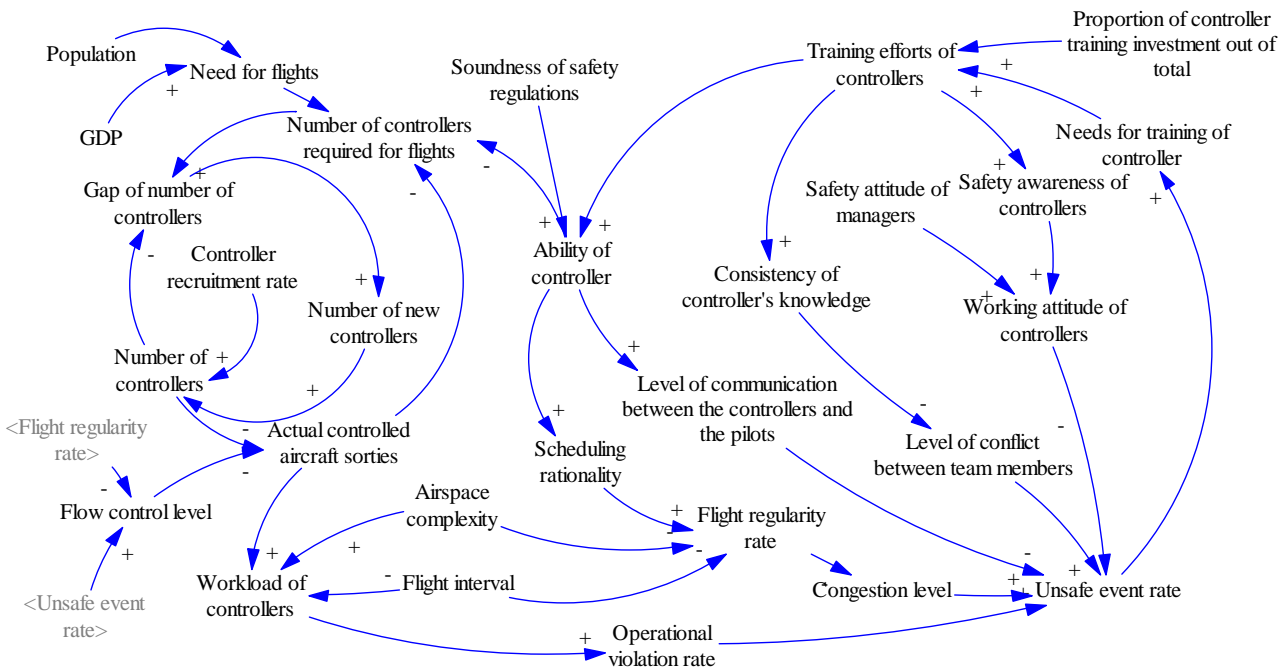

Fig. 2. Causal loop diagram of the control department subsystem

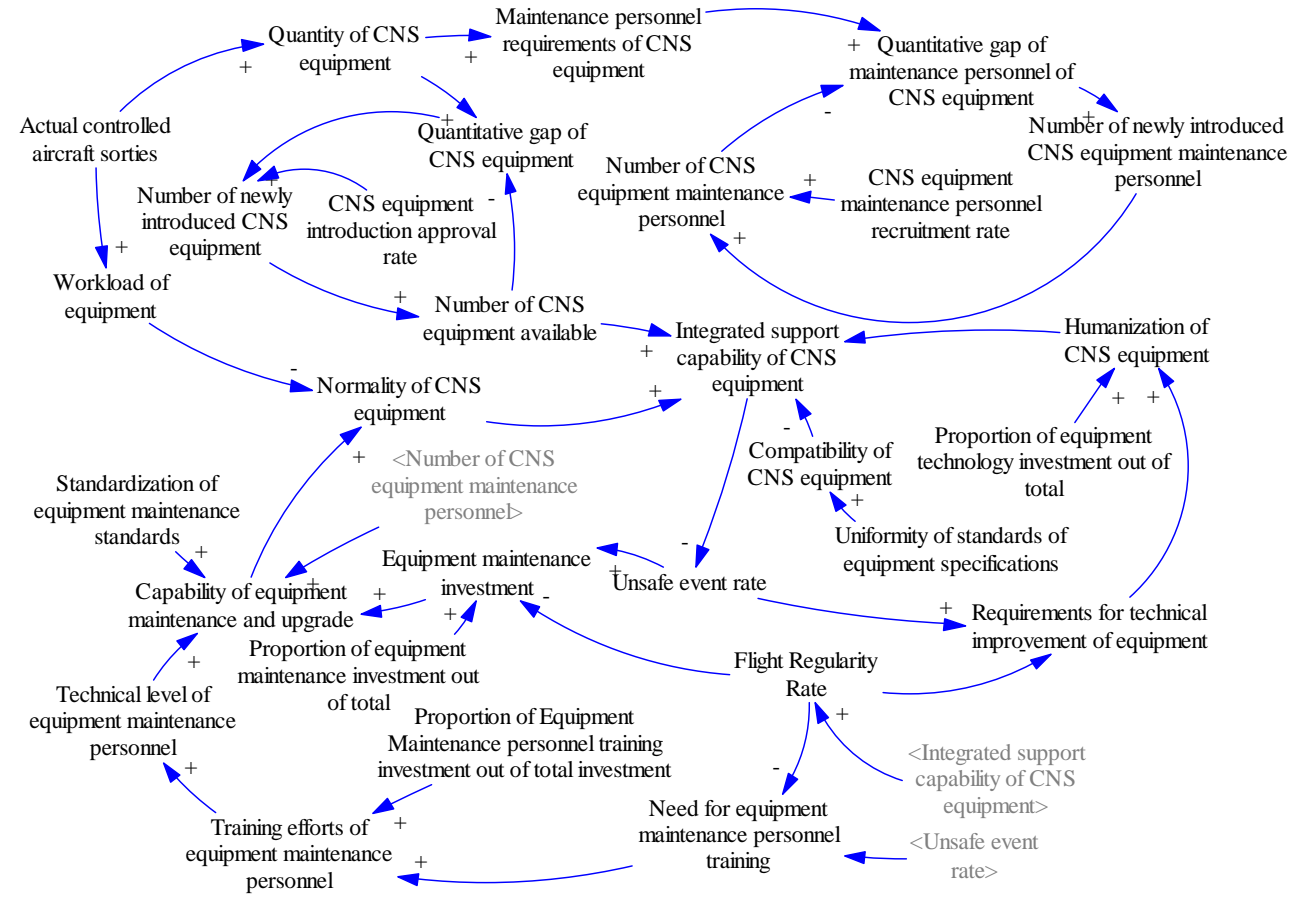

Fig. 3. Causal loop diagram of the CNS department subsystem 
Subsystem for the sustainable and safe development of the communication, navigation, and surveillances (CNS) department

The equipment is the direct carrier for the controller to perform air traffic control. An increase in the number flights leads to the demand for increasing the number, automation [20], and humanization [21] of equipment. Equipment support is the basic guarantee for ATC safety [22], and the quantity and quality of equipment maintenance personnel are the source power for the quality of ATC equipment assurance [14]. If the compatibility is good, the integration and sharing between devices will be good and the connection will be seamless. With the increase of sorties, the equipment workload increase continuously and equipment failure occur more frequently. This reduces the comprehensive support capability of equipment and leads to frequent unsafe event. Complex type brought great difficulties to the daily maintenance of equipment. The reduction of normality and safety performance will, in turn, restrict the sustainable and safe development of ATC units. So, the causal loop diagram of the CNS department subsystem shown in Figure 3.

\section{Subsystem for the sustainable and safe development of meteorology department}

The increase in controlled aircraft sorties increases the requirements for meteorological service quality [19]. The more flights there are, the smaller the time intervals of meteorological observation. The shortening of observation time intervals not only increases the workload of meteorological personnel, but also increases the workload of meteorological observation equipment, causing unsafe event and flight irregularity. Therefore, it is necessary to increase the input of the technical support and the training of meteorological personnel, so as to improve the quality of meteorological personnel and ensure the accuracy of observations. The increase of the unsafe event rate and the decrease of the flight regularity rate caused by meteorological factors inhibit development, as ATC units will take measures of flow control to reduce the number of flights. So, the causal loop diagram of the meteorology department subsystem Figure 4.

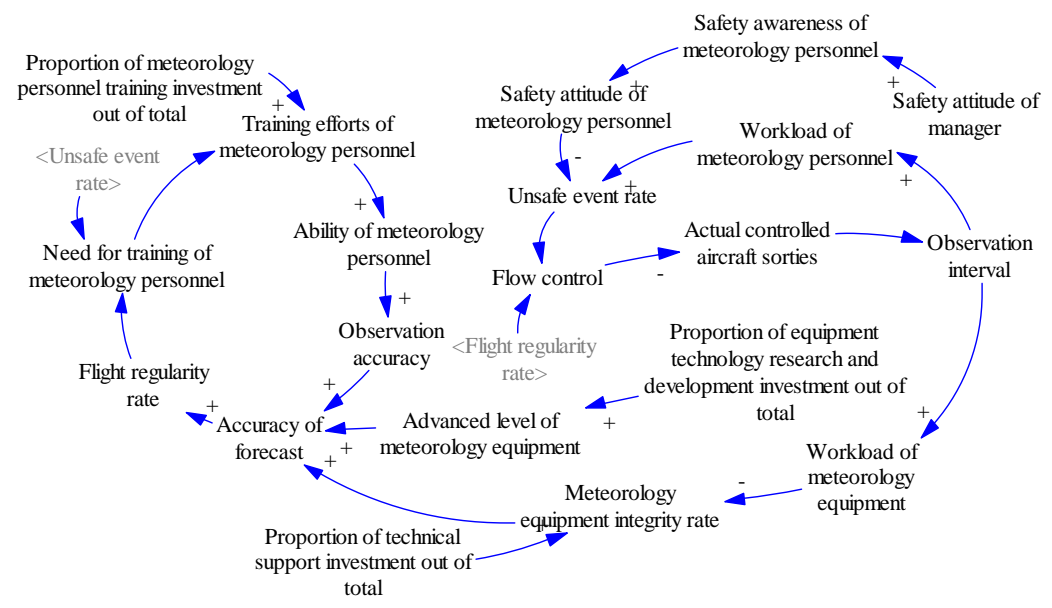

Fig. 4. Causal loop diagram of the meteorology department subsystem 
Subsystem for the sustainable and safe development of information department

The quality and workload of the information personnel affects the accuracy of information which have interaction with perfection of information reporting regulations. More investment in the training is benefit of ability of information personnel. The higher the safety awareness and ability can reduce the unsafe event rate. The increase in controlled aircraft sorties increases the workload in receiving and dispatching information, thus increasing the workload of the information personnel, resulting fatigue and "mistakes, forgetfulness and omission". Altogether, these restrict the development of ATC units. So, the causal loop diagram of the information department subsystem in Figure 5.

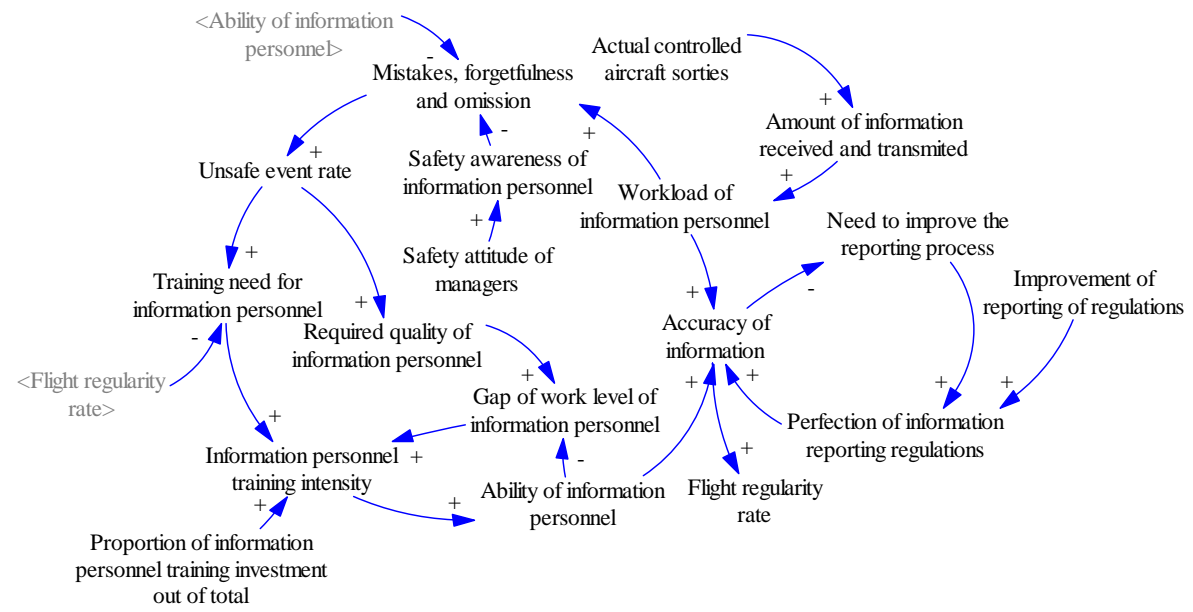

Fig. 5. Causal loop diagram of the information department subsystem

\section{Flow diagram}

According to the analysis in "Causal loop diagram", the four subsystems are connected by actual controlled aircraft sorties, unsafe event rate, the flight regularity rate. The variables in the causal loop diagram are divided into four categories (stock, flow, auxiliary, and exogenous). Then the flow diagram in Figure 6 was built. The policy variables and observation variables are shown in Table 1. 


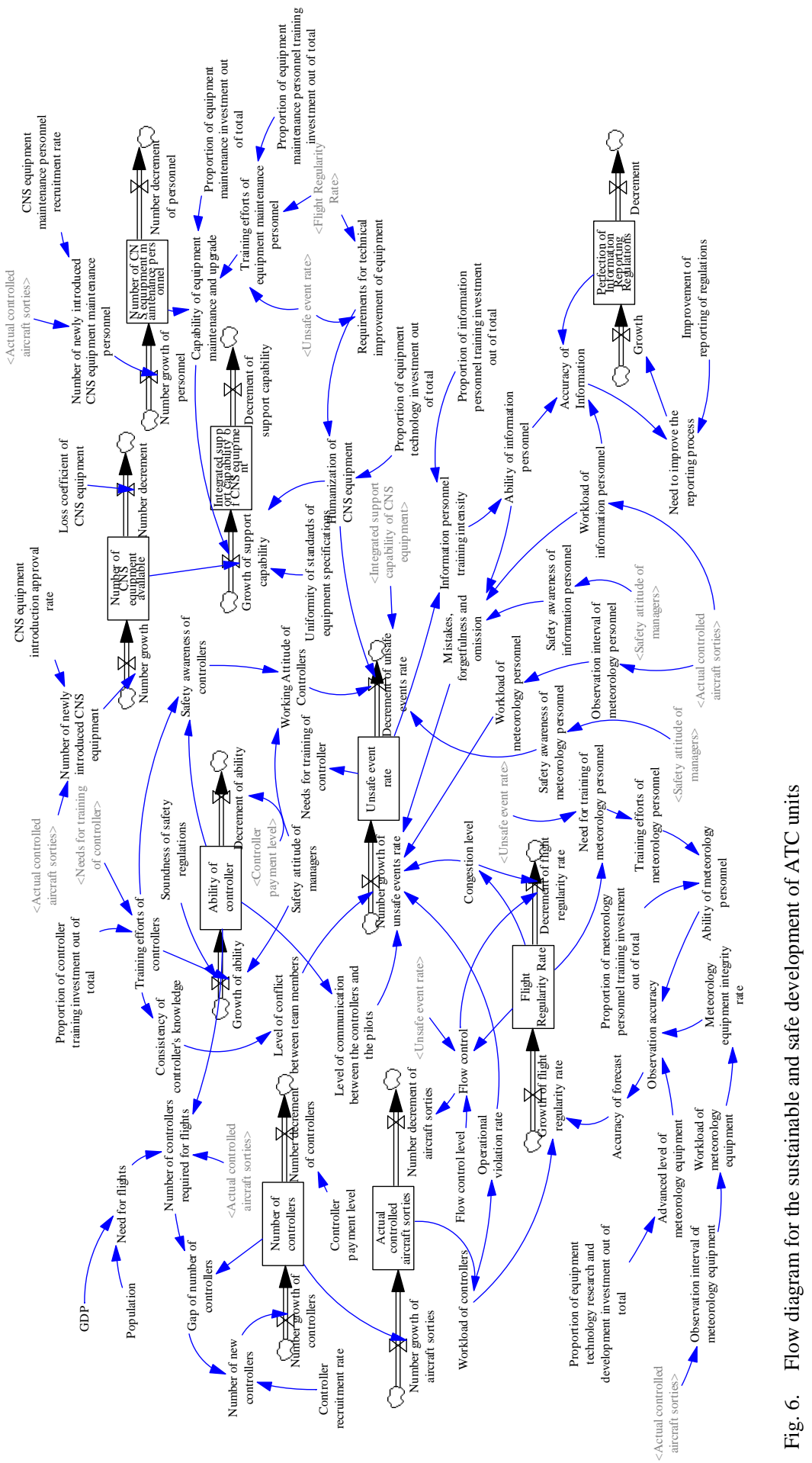


Policy variables and observation variables

\begin{tabular}{|c|c|c|}
\hline Business areas & Policy variables & Observation variables \\
\hline \multirow{6}{*}{ Control } & Controller recruitment rate & \multirow{20}{*}{$\begin{array}{l}\text { Unsafe event rate } \\
\text { Flight regularity rate } \\
\text { Actual controlled aircraft } \\
\text { sorties }\end{array}$} \\
\hline & Controller payment level & \\
\hline & Proportion of controller training investment out of total & \\
\hline & Flow control level & \\
\hline & Safety attitude of managers & \\
\hline & Soundness of safety regulations & \\
\hline \multirow{7}{*}{$\begin{array}{c}\text { Communication, } \\
\text { navigation, and } \\
\text { surveillance }\end{array}$} & CNS equipment maintenance personnel recruitment rate & \\
\hline & CNS equipment introduction approval rate & \\
\hline & Proportion of equipment technology investment out of total & \\
\hline & Proportion of equipment maintenance investment out of total & \\
\hline & $\begin{array}{l}\text { Proportion of equipment maintenance personnel training } \\
\text { investment out of total }\end{array}$ & \\
\hline & Uniformity of standards of equipment specifications & \\
\hline & Standardization of equipment maintenance standards & \\
\hline \multirow{4}{*}{ Meteorology } & Safety attitude of managers & \\
\hline & $\begin{array}{l}\begin{array}{l}\text { Proportion of meteorology personnel training investment out } \\
\text { of total }\end{array} \\
\end{array}$ & \\
\hline & Proportion of technical support investment out of total & \\
\hline & $\begin{array}{l}\text { Proportion of equipment technology research and } \\
\text { development investment out of total }\end{array}$ & \\
\hline \multirow{3}{*}{ Information } & $\begin{array}{l}\text { Proportion of information personnel training investment out } \\
\text { of total }\end{array}$ & \\
\hline & Improvement of reporting of regulations & \\
\hline & Safety attitude of managers & \\
\hline
\end{tabular}

\section{Application of system dynamic model of ATC units}

The air traffic control units are divided into three categories, namely, the air traffic management bureau of the Civil Aviation Administration, the regional air traffic management bureau and the air traffic control sub-bureau (air traffic control station). The air traffic management bureau of the Civil Aviation Administration has no operational entity Regional air traffic management bureaus are responsible for the coordination of local operation and the whole region. Air traffic control sub-bureaus and air traffic control stations fully perform operation duties, but the operation business of air traffic control stations is not perfect. Therefore, we focus on the ATC sub-bureau.

Tianjin ATC Sub-bureau has departments of control, meteorological, information, and communication, and each department has complete operation procedures, mature management system, and powerful personnel and equipment support capacity. The operation system is relatively large, in line with the basic characteristics of a complex system. According to the historical data of Tianjin ATC sub-bureau, the development and support capability increase year by year. On the premise that the support capability and development level are improving, the rate of unsafe event should show a stable trend, but the rate of unsafe event is on the rise. This fully reflects the mismatch between the support capability and its development level, and provides a foundation for exploring the relationship between safety, support capability and development.

Therefore, taking Tianjin ATC sub-bureau as an example, the system dynamics model for the sustainable and safe development of ATC units was applied. 


\section{Equation and parameter estimation}

There are three ways to establish the parameters in the model. First, data collection and interviews are used to obtain relevant parameters. The second is to use the statistical regression. Third, the table function method can be used. According to the different properties of variables, the main equations can be divided into three categories: stock equation, flow equation, and auxiliary variable equation. The main variables and equations in the model are shown in Table 2.

Main variables and equations in the model

\begin{tabular}{|c|c|c|c|}
\hline Variable type & Variable name & Equation & Unit \\
\hline \multirow{4}{*}{ State variable } & Number of controllers & INTEG (increment-decrement, initial value) & [person] \\
\hline & Actual controlled aircraft sorties & INTEG (increment-decrement, initial value) & [sortie] \\
\hline & Flight regularity rate & INTEG (increment-decrement, initial value) & {$[-]$} \\
\hline & Unsafe event rate & INTEG (increment-decrement, initial value) & {$[-]$} \\
\hline \multirow{4}{*}{ Rate variable } & Number growth of controllers & DELAY1 (Number of new controllers, 1) & [person] \\
\hline & $\begin{array}{c}\text { Number decrement of CNS } \\
\text { equipment available }\end{array}$ & $\begin{array}{c}\text { Number of CNS equipment available* Loss } \\
\text { coefficient of CNS equipment }\end{array}$ & {$[-]$} \\
\hline & $\begin{array}{l}\text { Number decrement of aircraft } \\
\text { sorties }\end{array}$ & Actual controlled aircraft sorties $*$ Flow control & [sortie] \\
\hline & Decrement of ability of controller & $\begin{array}{c}\text { IF THEN ELSE (Controller payment level > 0.5, } \\
\left.0,-0.3^{*} \text { Controller payment level }+0.2\right)\end{array}$ & {$[-]$} \\
\hline \multirow{4}{*}{$\begin{array}{l}\text { Auxiliary } \\
\text { variable }\end{array}$} & $\begin{array}{l}\text { Consistency of controller's } \\
\text { knowledge } \\
\end{array}$ & $\begin{array}{l}\text { IF THEN ELSE (Training efforts of controllers } \\
<0.5,0.5 \text {, Training efforts of controllers) }\end{array}$ & {$[-]$} \\
\hline & Congestion level & $\begin{array}{c}\text { IF THEN ELSE(Flight regularity rate }<0.5,1,2-2 * \\
\text { Flight regularity rate) }\end{array}$ & {$[-]$} \\
\hline & $\begin{array}{l}\text { Mistakes, forgetfulness and } \\
\text { omission }\end{array}$ & $\begin{array}{c}(- \text { Safety awareness of information } \\
\text { personnel }+1) * 0.3+\text { Workload of information } \\
\text { personnel*0.4+(-Ability of information } \\
\text { personnel }+1) * 0.3\end{array}$ & {$[-]$} \\
\hline & Accuracy of information & $\begin{array}{c}\text { Perfection of information reporting } \\
\text { Regulations } * 0.3+\text { Ability of information } \\
\text { personnel } * 0.5+(- \text { Workload of information } \\
\text { personnel }+1) * 0.2\end{array}$ & {$[-]$} \\
\hline
\end{tabular}

\section{Model validation and test}

The process of consistency validation and structure test helps to establish the credibility of the model. The simulated data and historical data of the unsafe event rate and actual controlled aircraft sorties from 2008 to 2018 are compared and analysed to verify whether the model is valid. The maximum error of actual controlled aircraft sorties is $8.2 \%$, and the average relative error is $3.00 \%$. The maximum error of unsafe event rate is $10.3 \%$, and the average relative error is $4.3 \%$. The error is within the acceptable range [23], so the model can be used for scenario simulation.

\section{Scenario simulation and result analysis}

\section{Original policy simulation}

Under current safety policy, we input actual data of the Tianjin ATC sub-bureau from the year 2019 into the model. The trends of actual controlled aircraft sorties, the unsafe 
event rate, and the flight regularity rate of the Tianjin ATC sub-bureau from 2019-2036 was shown in Figure 7. The step length was 1, the unit was year, and the simulation time was 17 years.

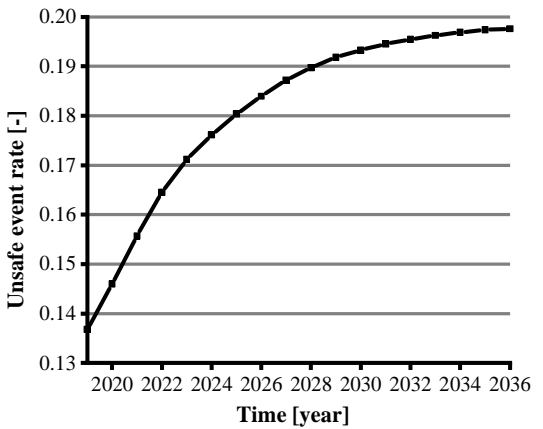

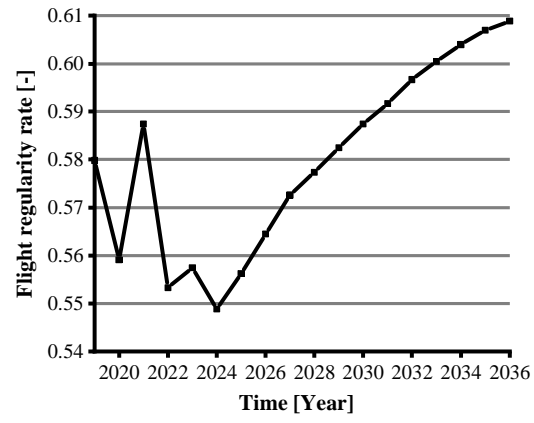

c)

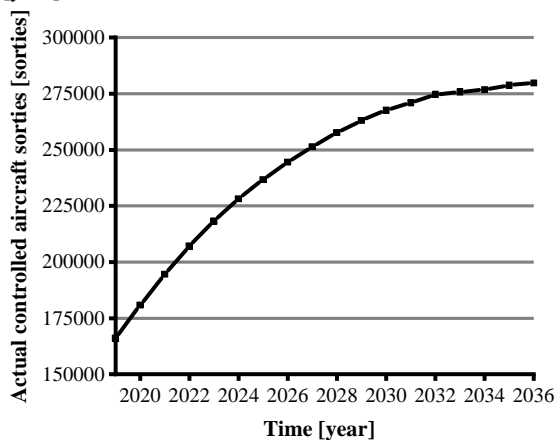

Fig. 7. Original policy simulation of Tianjin ATC sub-bureau: a) unsafe event rate, b) flight regularity rate, c) actual controlled aircraft sorties

According to Figure $7 \mathrm{a}$, with the current policies, the unsafe event rate will keep increasing. According to Figure $7 \mathrm{~b}$, with the current safety capacity and development level, the flight regularity rate will show a downward trend from 2020 to 2024, reaching a minimum of 0.55 in 2024. After 2024, although it will show an upward trend, the growth will be slow. Then the flight regularity rate will reach 0.608 in 2036 , which does not meet the safety target of 0.7 or above, hardly meet the requirement of sustainable and safe development. According to Figure 7c, the number of aircraft sorties show linear growth from 2019 to 2024, with an annual increase of about 15,000. After 2024, the number of aircraft sorties will grow slowly, reaching saturation and maintaining the level at 270,000 after 2031. Under the current policies, it is difficult to achieve the growth rate of $10 \%$ from 2024 to 2036.

\section{Scenario simulation for the sustainable and safe development}

We determined main variables through the scenario simulation in a single business field. These variables include: Controller pay level (V1), Proportion of controller training investment out of total (V2), Flow control level (V3), Proportion of equipment maintenance investment out of total (V4), Uniformity of standards of equipment specifications (V5), Safety attitude of managers (V6), Proportion of equipment technology research and 
development investment out of total (V7), and Proportion of information personnel training investment out of total (V8). These variables are divided into two categories: one represents the development capability of the Tianjin ATC sub-bureau, and the other represents the support capability, so as to design three policy scenarios for sustainable development.

\section{Maintain support capability but decrease development}

Keeping the support capability, we ran a simulation to observe the level of development when safety performance targets and flight regularity targets achieve. Through model debugging, under the condition that the simulated value of flow control level began at 0.55 , it rose to 0.65 (Policy a) and 0.8 (Policy b), to observe the variation trend in these three policies.

a)

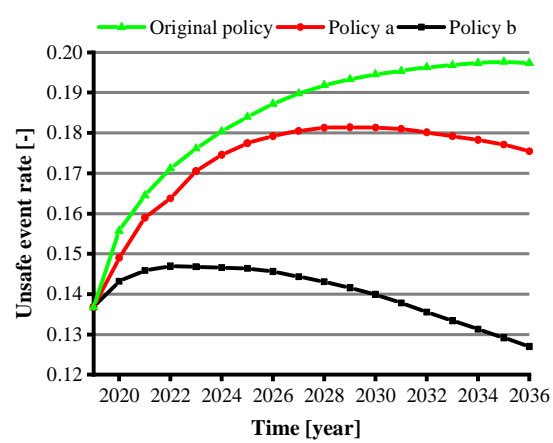

b)

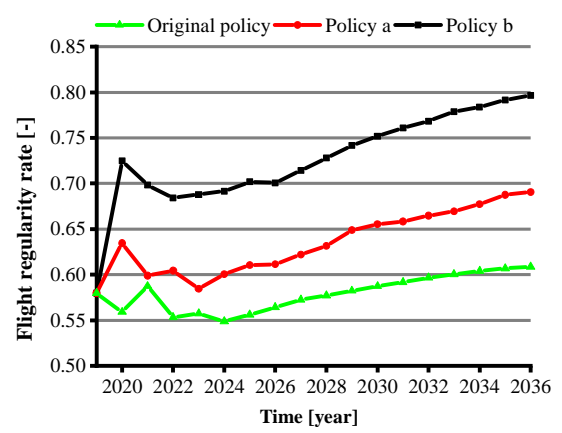

c)

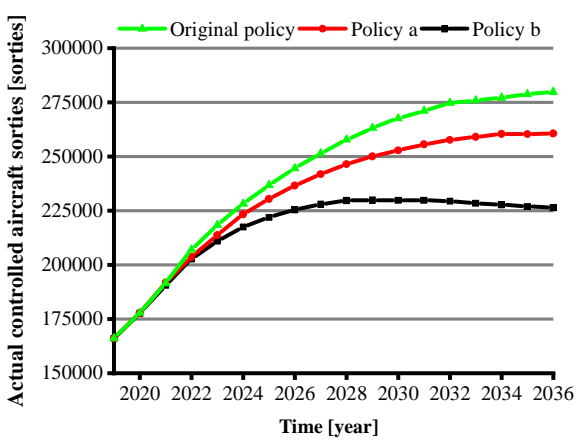

Fig. 8. Maintaining the support capability but decreasing the development of Tianjin ATC sub-bureau: a) unsafe event rate, b) flight regularity rate, c) actual controlled aircraft sorties

It can be seen from Figure 8 that when the flow control level was raised from 0.55 to 0.8 , the unsafe event rate was significantly improved from 2019-2036. After 2024, the unsafe event rate shows a downward trend. Meanwhile, flight regularity would be significantly increased after 2022, reaching 0.79 in 2036. Although strict flow control can significantly improve the unsafe event rate and flight regularity, it would also affect the development of flights. As a result, the actual controlled aircraft sorties would be reduced by nearly 50,000 compared with the original policies, and the annual growth rate of $10 \%$ could not be achieved. 


\section{Maintain development but increase the support capability}

Through the orthogonal table of $\operatorname{L} 18\left(3^{\wedge} 7\right)$, policies are combined to determine the policy scenarios. This paper selects five policy scenarios, which set in Table 3.

Policy scenarios

\begin{tabular}{|c|c|c|c|c|c|c|c|}
\hline Policy & V1 & V2 & V4 & V5 & V6 & V7 & V8 \\
\hline Policy 1 & 0.5 & 0.2 & 0.1 & 0.35 & 0.5 & 0.1 & 0.2 \\
\hline Policy 2 & 0.5 & 0.3 & 0.15 & 0.4 & 0.6 & 0.15 & 0.25 \\
\hline Policy 3 & 0.7 & 0.3 & 0.25 & 0.5 & 0.7 & 0.2 & 0.25 \\
\hline Policy 4 & 0.6 & 0.2 & 0.1 & 0.4 & 0.7 & 0.15 & 0.3 \\
\hline Policy 5 & 0.6 & 0.35 & 0.15 & 0.5 & 0.5 & 0.2 & 0.2 \\
\hline Policy 6 & 0.6 & 0.35 & 0.25 & 0.35 & 0.6 & 0.1 & 0.3 \\
\hline Policy 7 & 0.5 & 0.2 & 0.15 & 0.35 & 0.7 & 0.2 & 0.25 \\
\hline Policy 8 & 0.7 & 0.3 & 0.25 & 0.4 & 0.5 & 0.1 & 0.3 \\
\hline Policy 9 & 0.7 & 0.35 & 0.1 & 0.5 & 0.6 & 0.15 & 0.2 \\
\hline Policy 10 & 0.5 & 0.2 & 0.2 & 0.5 & 0.5 & 0.15 & 0.25 \\
\hline Policy 11 & 0.5 & 0.2 & 0.1 & 0.35 & 0.86 & 0.2 & 0.3 \\
\hline Policy 12 & 0.5 & 0.3 & 0.15 & 0.4 & 0.7 & 0.1 & 0.2 \\
\hline Policy 13 & 0.6 & 0.2 & 0.15 & 0.5 & 0.6 & 0.1 & 0.3 \\
\hline Policy 14 & 0.6 & 0.3 & 0.25 & 0.35 & 0.7 & 0.15 & 0.2 \\
\hline Policy 15 & 0.6 & 0.35 & 0.1 & 0.4 & 0.5 & 0.2 & 0.25 \\
\hline Policy 16 & 0.7 & 0.2 & 0.25 & 0.4 & 0.85 & 0.2 & 0.2 \\
\hline Policy 17 & 0.7 & 0.3 & 0.1 & 0.5 & 0.7 & 0.1 & 0.25 \\
\hline Policy 18 & 0.7 & 0.3 & 0.15 & 0.3 & 0.5 & 0.15 & 0.3 \\
\hline
\end{tabular}

a)

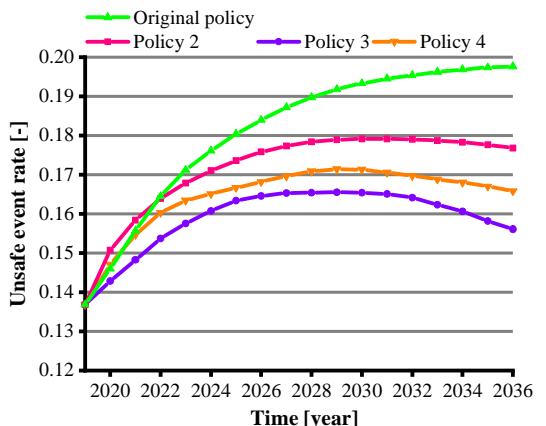

b)

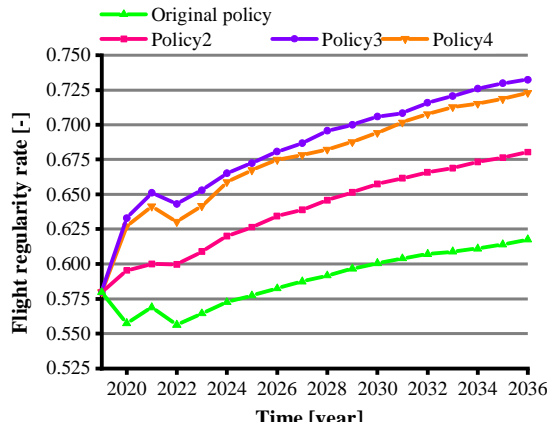

c)

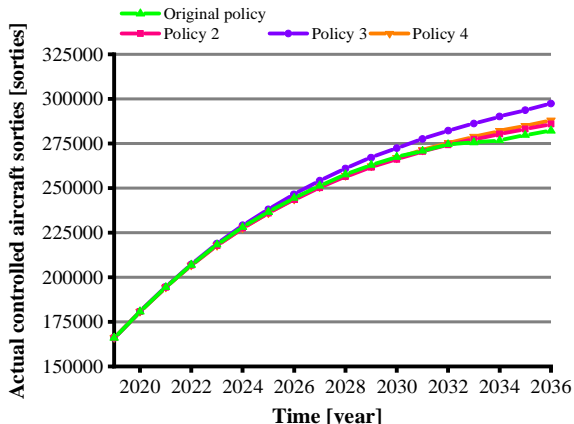

Fig. 9. Maintaining development but increasing the support capability of Tianjin ATC sub-bureau: a) unsafe event rate, b) flight regularity rate, c) actual controlled aircraft sorties 
For clarity, this article only shows Policy 2, Policy 3, and Policy 4 in Figure 9. According to Figure 9a, Policy 3 can minimize the rate of unsafe event. According to Figure 9b, Policy 3 can significantly improve the flight regularity after 2022, reaching 0.733 in 2036 . Through the policy scenario simulation, it was found that the best policy combination is Policy 3 . Separately adjusting the support capability can improve the unsafe event rate and flight regularity rate, but there would be a delay for 2-3 years. According to Figure 9c, adjustments to the support capability alone would not cause the number of controlled aircraft sorties to grow significantly. On the one hand, traffic control is not relaxed; on the other hand, only raising the level of support capability but not changing the development led to mismatch between the development level and the support capability, thus limiting the growth of actual controlled aircraft sorties.

\section{Sustainable and safe development}

Considering the advantages and disadvantages of the above schemes, it is necessary to reduce the development level while increasing the support capability in 2023. After the delay of the support capability, the current development level and support capability will be maintained.

Taking advantage of the simulation game in VENSIM, we set the support capability according to policy 3 in the simulation in 2019. The traffic control level reached up to 0.8 in 2019-2023, then, reduced to 0.45 in 2024. The specific collocation scheme is in Table 4.

Policy scenarios

\begin{tabular}{|c|c|c|c|c|c|c|c|c|}
\hline Policies & V1 & V2 & V4 & V5 & V6 & V7 & V8 & V3 \\
\hline Original policy & 0.5 & 0.25 & 0.15 & 0.3 & 0.55 & 0.1 & 0.2 & 0.55 \\
\hline $\begin{array}{c}\text { Policy for } \\
\text { sustainable and } \\
\text { safe development }\end{array}$ & 0.6 & 0.35 & 0.2 & 0.5 & 0.7 & 0.2 & 0.3 & $\begin{array}{c}2019-20230.8 \\
2024-20360.45\end{array}$ \\
\hline
\end{tabular}

According to Figure 10, the unsafe event rate of the Tianjin ATC sub-bureau would be significantly decreased, reaching 0.121 million by 2036 . The flight regularity rate would be significantly improved compared with the traditional development pattern, reaching 0.83 in 2036. The trends of unsafe event rate and flight regularity rate show that the support capacity of Tianjin ATC sub-bureau can meet the needs of development. The number of aircraft from 2019 to 2023 would be lower than that in the traditional development pattern, while after 2024 it would be higher than the traditional development pattern and reach nearly 700 million by 2036. Thus, this simulation can achieve the development target of a $10 \%$ annual growth rate. Although the development level will be limited under the strict flow control at the beginning, the safety level and the flight regularity will be guaranteed. After the release of the flow control, the support capacity has been greatly improved to meet the needs of rapid development. Under this scenario, Tianjin ATC sub-bureau can achieve sustainable development. 
a)

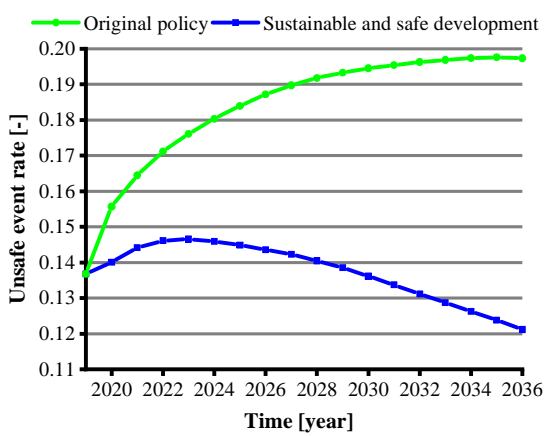

b)

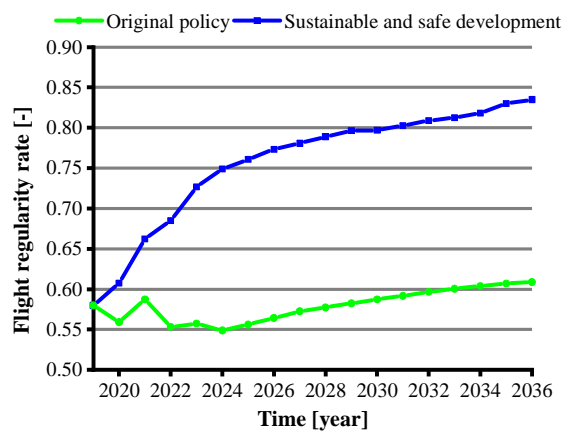

c)

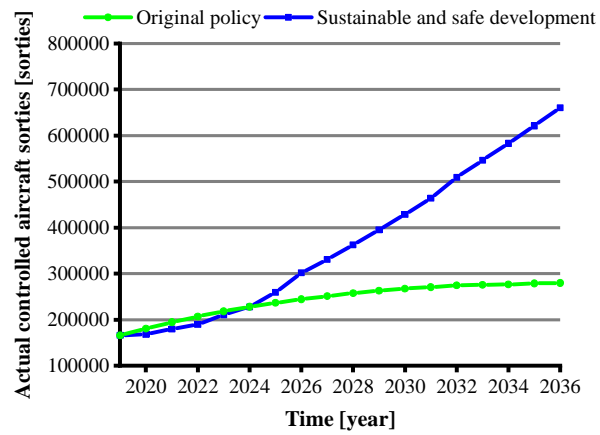

Fig. 10. Sustainable and safe development of Tianjin ATC sub-bureau: a) unsafe event rate, b) flight regularity rate, c) controlled aircraft sorties

\section{Conclusion}

Due to the numerous factors and complexity of ATC units, the relationship between unsafe event and flight regularity is difficult to predict. Therefore, this paper aimed to build a system dynamics model for the sustainable and safe development of ATC units based on system archetype "growth and underinvestment", taking into account the subsystems of control; communication, navigation and surveillance; meteorology; and information. The model explains the complex interaction feedback mechanism and dynamic mechanism of air traffic control system factors, showing that system dynamics can be used to describe complex ATC systems.

This paper uses the real data of Tianjin ATC sub-bureau to analyse the trend of safety and development. According to the situation analysis results, Tianjin ATC sub-bureau cannot achieve the sustainable safety development goal. Tianjin ATC sub-bureau need to realize the time delay and adjust the support capability and development level timely and scientifically. However, only linear and single adjustment of support capacity or development level cannot ensure the sustainable and safe development, so it is necessary to coordinate them, and the model provide a way.

This paper put forward policy scenarios for sustainable development of Tianjin ATC sub-bureau. In 2019-2023, reduce the development level while increasing the support capability, in 2024-2036 to relax traffic control: in 2019-2023, increase "controller pay level" by $10 \%$, increase "proportion of controller training investment out of total" by $10 \%$, 
increase "safety attitude of managers" by $15 \%$, increase "Proportion of equipment technology research and development investment out of total" by $10 \%$, and cut $25 \%$ flights; in 2024-2036, releasing the flow control to $45 \%$ while maintaining the same support capability.

The model can simulate the trends of the unsafe event rate, the flight regularity rate, and the actual number of controlled aircraft sorties under different scenarios. In the process of the rapid growth of the number of flights, this model can support policy decisions for ATC units to improve the support of capability in a gradient, step-by-step, planned way, so as to realize the sustainable and safe development of ATC units. The dynamic model of ATC unit sustainable safety development established in this paper is simulated with Tianjin ATC sub-bureau as an example, showing that the model can be extended to other ATC units and fields for decision support for complex systems.

\section{References}

[1] Arblaster M, Zhang C. Liberalisation of airport air traffic control: A case study of Spain. Transp Policy. 2020;91:38-47. DOI: 10.1016/j.tranpol.2020.03.003.

[2] Galvin JJ. Air Traffic Control Resource Management Strategies and the Small Aircraft Transportation System: A System Dynamics Perspective [PhD Thesis]. Blacksburg: Virginia Polytechnic Institute \& State University; 2002. Available from: https://www.researchgate.net/publication/242281854_Air_traffic_control_ resource_management_strategies_and_the_small_aircraft_transportation_system_A_system_dynamics_pers pective.

[3] Kistan T, Gardi A, Sabatini R, Ramasamy S, Batuwangala E. An evolutionary outlook of air traffic flow management techniques. Prog Aerosp Sci. 2017;88:15-42. DOI: 10.1016/j.paerosci.2016.10.001.

[4] Cooke DL, Rohleder TR. Learning from incidents: from normal accidents to high reliability. Syst Dyn Rev. 2006;22(3):27. DOI: 10.1002/sdr.338.

[5] Chen F, Liu LL. Research on safety services capability model for ATC service in ATM division. Energy Procedia. 2012;17(1):1369-75. DOI: 10.1016/j.egypro.2012.02.254.

[6] Forrester JW. System dynamics, systems thinking, and soft OR. Syst Dyn Rev. 1994;10(2-3):245-56. DOI: $10.1002 /$ sdr.4260100211.

[7] Forrester JW. System dynamics - a personal view of the first fifty years. Syst Dyn Rev. 2007;23(2-3):345-58. DOI: 10.1002/sdr.382.

[8] Bouloiz H, Garbolino E, Tkiouat M, Guarnieri F. A system dynamics model for behavioral analysis of safety conditions in a chemical storage unit. Safety Sci. 2013;58:32-40. DOI: 10.1016/j.ssci.2013.02.013.

[9] Han SU, Saba F, Lee SH, Y Mohamed, Peña-Mora F. Toward an understanding of the impact of production pressure on safety performance in construction operations. Accid Anal Prev. 2014;68(1):106-16. DOI: 10.1016/j.aap.2013.10.007.

[10] Vafa-Arani H, Jahani S, Dashti H, Heydari J, Moazen S. A system dynamics modeling for urban air pollution: A case study of Tehran, Iran. Transportation Res Part D: Transport Environ. 2014;31(31):21-36. DOI: 10.1016/j.trd.2014.05.016.

[11] Yao H, Shen L, Tan Y, Hao J. Simulating the impacts of the policy scenarios on the sustainability performance of infrastructure projects. Automat Constr. 2011;20(8):1060-9. DOI: 10.1016/j.autcon.2011.04.007.

[12] Shin M, Lee HS, Park M, Moon M, Han S. A system dynamics approach for modeling construction workers' safety attitudes and behaviors. Accid Anal Prev. 2014;68(2):95-105. DOI: 10.1016/j.aap.2013.09.019.

[13] Suryani E, Chou SY, Hartono R, Chen CH. Demand scenario analysis and planned capacity expansion: A system dynamics framework. Simul Modelling Practice Theory. 2010;18(6):732-51. DOI: 10.1016/j.simpat.2010.01.013.

[14] Lyneis JM. System dynamics for market forecasting and structural analysis. Syst Dyn Rev. 2000;16(1):3-25. DOI: $10.1002 /($ sici)1099-1727(200021)16:1<3::aid-sdr183>3.0.co;2-5.

[15] Peter S. The fifth discipline. The United States: Random House Audio; 1999. ISBN: 9780553456349.

[16] Sama M, D'Ariano A, D'Ariano P, Pacciarelli D. Optimal aircraft scheduling and routing at a terminal control area during disturbances. Transportation Res Part C: Emer Technol. 2014;47:61-85. DOI: 10.1016/j.trc.2014.08.005. 
[17] Loft S, Sanderson P, Neal A, Mooij M. Modeling and predicting mental workload in en route air traffic control: critical review and broader implications. Hum Factors. 2007;49(3):376-99. DOI: 10.1518/001872007x197017.

[18] Pandey MM, Shukla D, Graham A. Evaluating the human performance factors of air traffic control in Thailand using Fuzzy Multi Criteria Decision Making method. J Air Transp Manage. 2019;8:101708. DOI: 10.1016/j.jairtraman.2019.101708.

[19] Mearns K, Kirwan B, Reader TW, Jackson J, Kennedy R, Gordon R. Development of a methodology for understanding and enhancing safety culture in Air Traffic Management. Safety Sci. 2013;53:123-33. DOI: 10.1016/j.ssci.2012.09.001.

[20] Chang YH, Yeh CH. Human performance interfaces in air traffic control. Appl Ergon. 2010;41(1):123-9. DOI: $10.1016 /$ j.apergo.2009.06.002.

[21] Subotic B, Ochieng WY, Straeter O. Recovery from equipment failures in ATC: Determination of contextual factors. Reliab Eng Syst Saf. 2007;92(7):858-70. DOI: 10.1016/j.ress.2006.04.023.

[22] Ali BS, Majumdar A, Ochieng WY, Schuster W, Chiew TK. A causal factors analysis of aircraft incidents due to radar limitations: The Norway case study. J Air Transp Manage. 2015;44-45:103-9. DOI: 10.1016/j.jairtraman.2015.03.004.

[23] Sterman JD. Systems simulation. Expectation formation in behavioral simulation models. Syst Res Behav Sci. 1987;32(3):190-211. DOI: 10.1002/bs.3830320304. 